\title{
Dokumentasi Keperawatan
}

\author{
salsabnafiah@gmail.com
}

\section{Latar Belakang}

Keperawatan merupakan suatu bentuk layanan kesehatan professional yang merupakan bagian integral dari layanan kesehatan berbasis ilmu dan kiat keperawatan, yang berbentuk layanan bio-psiko-sosio-spritual komprehensif yang ditunjukkan bagi individu, keluarga, kelompok, dan masyarakat baik sehat maupun sakit, yang mencakup keseluruhan proses kehidupan manusia (Lokakarya Keperawatan Nasional, 1983). Kontribusi keperawatan dalam meningkatkan derajat kesehatan masyarakat didasarkan pada beberapa konsep keperawatan. Pertama, asuhan yang diberikan perawat bersifat holistic-menyeluruh pada semua aspek "manusia" klien, bukan berfokus pada aspek biologis semata. Kedua, sasaran asuhan keperawatan adalah klien, mulai tingkat individu sampai tingkat masyarakat. Ketiga, lingkup layanan keperawatan bukan terbatas pada klien yang sakit saja, tetapi juga klien yang sehat.

Sebagai seorang perawat professional memerlukan pengantar proses keperawatan dalam melakukan tindakan keperawatan. Untuk mencapai pelayanan keperawatan yang professional diperlukan proses keperawatan yang sistematika. Proses keperawatan tentunya bukan sesuatu hal yang asing bagi Anda, karena setiap hari anda bergelut dengan proses ini pada saat Anda memberikan pelanyanan keperawatan kepada pasien.

Apakah proses keperawatan itu? Proses keperawatan adalah suatu cara atau metode yang sistematis dalam memberikan asuhan keperawatan yang dilakukan oleh perawat dan bekerjasama dengan pasien (induvidu, keluarga, masyarakat) yang bertujuan untuk mengidentifikasi masalah keperawatan dengan melakukan pengkajian, menentukan diagnosa, merencanakan tindakan yang akan dilakukan, melaksanakan tindakan serta mengevaluasi hasil asuhan keperawatan yang telah diberikan dengan berfokus pada pasien, berorientasi pada tujuan yang telah ditetapkan bersama.

Selanjutnya bagaimana tahapan proses keperawatan itu? Menurut Craven dan Hirnle bahwa proses keperawatan memiliki enam fase yaitu: pengkajian, diagnosa, tujuan, rencana tindakan, implementasi, dan evaluasi. Kemudian teori lain menyatakan bahwa proses keperawatan adalah sarana atau alat yang digunakan oleh seorang perawat dalam bekerja dan tata cara pelaksanaannya tidak boleh dipisah-pisah antara tahap pertama, kedua, ketiga dan seterusnya. Tahap pertama pengkajian, tahap kedua menegakkan diagnosa keperawatan, 
tahap ketiga Menyusun rencana keperawatan yang mengarah kepada penanganan diagnosa keperawatan, tahap keempat diimplementasikan dan tahap kelima atau tahap terakhir adalah dievaluasi. Orientasi dari pelayanan asuhan keperawatan adalah pada pencapaian tujuan asuhan keperawatan. Asuhan keperawatan baru dapat dikatakan berhasil dan selesai jika semua tujuan asuhan keperawatan yang telah ditetapkan dalam perencanaan keperawatan telah tercapai.

\section{Metode}

Metode yang digunakan untuk memperoleh informasi dan data yaitu menggunakan metode literasi membaca jurnal, buku, dan karya ilmiah lainnya.

\section{Hasil}

Melalui hasil literasi membaca jurnal, buku, dan karya ilmiah, didapatkan bahwa dalam dalam dokumentasi keperawatan memerlukan beberapa cara serta tahap agar data kesehatan dikumpulkan bersifat rinci dan akurat.

\section{Pembahasan}

\section{A. PENGERTIAN DOKUMENTASI PENGKAJIAN}

Dokumentasi pengkajian keperawatan merupakan catatan tentang hasil pengkajian yang dilaksanakan untuk mengumpulkan informasi dari pasien, membuat data dasar tentang pasien, dan membuat catatan tentang respons kesehatan pasien. Pengkajian yang komprehensif atau menyeluruh, sistematis yang logis akan mengarah dan mendukung pada identifikasi masalah-masalah pasien. Masalah-masalah ini dengan menggunakan data penkajian sebagai dasar formulasi yang dinyatakan sebagai diagnosa keperawatan.

\section{B. TUJUAN}

Metode dokumentasi dlam pengkajian keperawatan bertujuan untuk:

1. Mengumpulkan, mengorganisir, dan mencatat data yang menjelaskan respon manusia yang mempengaruhi pola-pola kesehatan pasien.

2. Hasil dokumentsi pengkajian akan menjadi dasar penulisan rencana asuhan keperawatan

3. Memberikan keyakinan tentang informasi dasar tentang kesehatan pasien untuk dijadikan referensi status kesehatannya saat ini atau yang lalu

4. Memberikan data yang cukup untuk menentukan strategi perawatan yang sesuai dengan kebutuhan pasien. 


\section{JENIS DOKUMENTASI PENGKAJIAN}

Dalam melaksanakan dokumentasi pada tahap pengkajian perlu diketahui bahwa jenis dokumentasi keperawatan meliputi:

1. Dokumentasi pada saat pengkajian awal (InitialAssessment)

Dokumentasi yang dibuat ketika pasien pertama kali masuk rumah sakit. Data yang dikaji pada pasien berupa data awal yang digunakan sebagai dasar dalam pemberian asuhan keperawatan.

2. Dokumentasi pengkajian lanjutan (Ongoing Assessment)

Data pada dokumentasi ini merupaka pengembangan dasar yang dilakukan untuk melengkapi pengkajian awal dengan tujuan semua data menjadi lengkap sehingga mendukung infromasi tentang permasalahan kesehatan pasien. Hasil pengkajian ini dimasukkan dalam catatan perkembangan terintegrasi pasien atau pada lembar data penunjang.

3. Dokumentasi pengkajian ulang (Reassessment)

Dokumentasi ini merupakan pencatatan terhadap hasil pengkajian yang didapat dari informasi selama evluasi. Perawat mengevauasi kemajuan dta terhadap pasien yang sudah ditentukan.

\section{JENIS DATA PADA PENGKAJIAN}

Dalam pengkajian keperawatan terdapat jenis data yang dapat diperoleh, yaitu:

\section{Data Subjektif}

Data subjektif diperoleh dari hasil pengkajian terhadap pasien dengan teknik wawancara, keluarga, konsultan, dan tenaga kesehatan lainnya serta riwayat keperawatan. Data ini berupa keluhan atau persepsi subjektif pasien terhadap status kesehatannya.

\section{Data Objektif}

Informasi data objektif diperoleh dari hasil observasi, pemeriksaan fisik, hasil pemeriksaan penunjang dan hasil laboratorium. Fokus dari pengkajian data objektif berupa status kesehatan, pola koping, fungsi status respons pasien terhadap terapi, risiko untuk masalah potensial, dukungan terhadap pasien. Karakteristik data yang diperoleh dari hasil pengkajian seharusnya memiliki karakteristik yang lengkap, akurat, nyata dan relevan. Data yang lengkap mampu mengidentifikasi semua masalah keperawatan pada pasien.

\section{E. METODE MEMPEROLEH DATA}

Untuk memperoleh data pada tahap pengkajian metode yang dapat digunakan perawat adalah:

1. Komunikasi Efektif Komunikasi dalam pengkajian keperawatan lebih dikenal dengan komunikasi terapeutik yang merupakan upaya mengajak pasien dan keluarga untuk bertukar pikiran dan perasaan. Untuk dapat memperoleh data yang akurat perawat perlu menjadi 
pendengar aktif terhadap keluhan pasien, adapun unsur yang menjadi pendengar yang aktif adalah dengan mengurangi hambatan dalam berkomunikasi, memperhatikan keluhan yang disampaikan oleh pasien dan menghubungkannya dengan keluhan yang dialami oleh pasien, mendengarkan dengan penuh perhatian apa yang dikeluhkan pasien, memberikan kesempatan pasien untuk menyelesaikan pembicaraannya, bersikap empati dan hindari untuk interupsi, berikan perhatian penuh pada saat berbicara dengan pasien. Data yang lengkap memerlukan upaya pengkajian yang fokus dan lebih komprehensif. Beberapa persyaratan yang harus dipenuhi agar data yang diperoleh menjadi data yang baik adalah menjaga kerahasiaan pasien, memperkenalkan diri, menjelaskan tujuan wawancara, pertahankan kontak mata serta mengusahakan agar saat pengkajian tidak tergesa-gesa.

\section{Observasi}

Observasi merupakan tahap kedua dari pengumpulan data. Pada pengumpulan data ini perawat mengamati perilaku dan melakukan observasi perkembangan kondisi kesehatan pasien. Kegiatan observasi meliputi sight, smell, hearing, feeling, dan taste. Kegiatan tersebut mencakup aspek fisik, mental, sosial dan spiritual.

\section{Pemeriksaan Fisik}

Pemeriksaan fisik dilakukan bersamaan dengan wawancara, yang menjadi fokus perawat pada pemeriksaan ini adalah kemampuan fungsional pasien. Tujuan dari pemeriksaan fisik ini adalah untuk menentukan status kesehatan pasien, mengidentifikasi masalah kesehatan dan mengambil data dasar untuk menentukan rencana tindakan perawatan. 


\section{Daftar Pustaka}

Budiono \& Sumirah. (2016). Konsep Dasar Keperawatan. Jakarta: Bumi Medika

Budiono. (2016). Konsep Dasar Keperawatan. Jakarta: Pubsdik SDM Kesehatan.

Dermawan, D. (2012). Proses Keperawatan Penerapan Konsep \& Karangka Kerja Yogyakarta: Gosyen

Erlin Ifadah. 2012. Penerapan Dokumentasi Keperawatan Elektronik Dalam Praktek

Keperawatan, Jakarta, FIK UI.

Herdman, T. H. (2018). NANDA-1 Diagnosis Keperawatan Definisi dan Klasifikasi 2018 2020. Jakarta: EGC.

Olfah Yustiana. (2016). Dokumentasi Keperawatan. Jakarta : : Pubsdik SDM Kesehatan.

Rachman, N. (2016). Applied Nanda, NIC, NOC, Pada Praktek Klinik Keperawatan Kebutuhan Dasar Manusia. Yogyakarta: Trans Medika

Rutami. (2012, Oktober). Pelaksanaan Proses Pengkajian Keperawatan di Ruang Rawat Inap RSUP H. Adam Malik Medan. Jurnal Keperawatan, 1(2).

Rosdahl, C. B., \& Kawalski, M. T. (2017). Buku Ajar Keperawatan Dasar. Jakarta: EGC.

Tarwoto, \& Wartono. (2015). Kebutuhan Dasar Manusia dan Proses Keperawatan. Yogyakarta: Salemba Medika.

Simamora. R. H. (2008) The correlation of ward chief's giving direction and command and the performance of on-duty nurses at Jember dr. Subandi general hospital inpatient wards. jurnal Administrasi dan Kebijakan Kesehatan, (https://fkm.unair.ac.id/jurnal-administr)

Simamora, R. H. (2019). Development of Guidelines for Applying appropriate Patient Identification to Achieve Patient Safety Goal

INC2019 12th International Nursing Conference. 2019.10455 - 455 (1 pages) UCI(KEPA) : I410-ECN-01012019-512-001224337 
